\title{
Game-Based Learning - Developing a Business Game for Interactive Architectural Visualization
}

\author{
Wolfgang Höhl \\ Department of Architecture \\ FH JOANNEUM - University of Applied Sciences Graz, Austria \\ wolfgang.hoehl@fh-joanneum.at
}

\begin{abstract}
We explored how game-based learning including open forms of teaching can improve teamwork, social skills and collaboration of inhomogeneous student groups. As open forms of teaching we used blended learning, open space technology (OST) and selected elements of gamification. Game-based learning approaches posit that learners who interact with educational materials with playful and dynamic tasks will learn better. To better understand improvement of teamwork, social skills and collaboration a specific business game with a defined amount of play tokens is introduced. Within this business game all participants $(n=22)$ will have to form interdisciplinary project teams to manage a professional 3D-visualization task. In three subsequent project stages (concept, development and implementation) all projects are continually evaluated and the teams are appropriately rewarded with play tokens. With these play tokens every team can purchase missing know-how or hire additional workforce. The final visualization project is evaluated by specific design criteria (qualitative) and by the remaining amount of play tokens (quantitative). The concept of a business game was a visible success. Open forms of teaching, such as blended learning and open space technology promote the active acquisition of basic knowledge, technical understanding and at least increase transfer competence. A continuous and transparent evaluation makes the individual learning progress directly tangible. Students who took part in the business game reported more enjoyment in learning the 3D visualization pipeline than students from the years before. The business game induced greater interest to the students in acquiring new content more easily and quickly than in the other courses. Also their high degree of personal responsibility led to outstanding new ideas and their own initiatives.
\end{abstract}

Index Terms-Game-based learning, Collaborative learning, Participatory design, Virtual reality, Computer games

\section{IntRoduction - CONNECTIVITY, COMMUNITY AND CONVENIENCE}

Student groups became continuously inhomogeneuos within the last five to ten years. Generally observable there was a remarkable change in digital media use, interaction habits, speed and the respective attention span. Using media and being affiliated to certain communities also lead to very particular habits, codes, preferences, social skills and individual conventions of the users. These phenomena were previously described by Weinreich et. al [1] and confirmed by studies by Koch and Frees [2] and Hartmann [3]. Scholz [4] describes the three 'c's - connectivity, community and convenience:

- 'Digital natives are online 24/7 ('connectivity').'

- 'Digital natives do nothing alone ('community').'

- 'Digital natives rely on convenience ('convenience').'
Additionally observable was a diminishing basic knowledge (e.g. in sketching, drawing and spatial imagination), a lack of general transfer competence and a retrogressively understanding of technical structures, as mentioned by Bleuel et. al [5]. A new form of sustainable teaching should reflect these problems in an appropriate way. Therefore this paper shows an efficient and game-based method for improved learning with inhomogeneous student groups.

Teaching is successful interaction. Learning is an active process with multiple partners. Today, students learn about their entire social environment, through analogue and digital media. Teaching and learning need appropriate framework conditions. Our new teaching concept is therefore based on forms of blended learning such as mentioned by Alexander [6], the open space technology by Owen [7], integrated forms of game-based learning and gamification, but also uses proven teaching formats such as excursions and guest lectures. Teaching and research are directly interwoven. Students learn best through their own (intrinsic) drive, through curiosity, a thirst for research and their own thirst for knowledge. Open forms of teaching should activate this intrinsic motivation. Practical and applied tasks as well as the direct contact with experts from business and industry should additionally motivate the students. In addition to the high practical relevance, theoretical modeling is an integral part of my teaching. Theoretical fundamentals should enable the student to develop transfer skills and solve future problems. Interdisciplinary tasks form an integral and important part of my teaching and should promote mutual interdisciplinary understanding. Students develop differently and at different speeds. In addition to specialist skills, soft skills and social skills need to be trained and developed. In interdisciplinary teamwork, different characters can complement each other.

Our new teaching concept in the shape of a business game integrates open forms of teaching, such as blended learning, open space technology (OST) and uses selected elements of gamification. Open forms of teaching (bar camp, open space) respond to the shorter individual attention span of the students. The intrinsic motivation of the students activates transfer competence, technological competence and the acquisition of basic knowledge. External digital offerings and familiar social networks are integrated into the lessons. The whole business game is carried out by the so called Sequential Evaluation Approach by Bowman [8] and Gabbard et. al. [9]. 
All work steps are carried out iteratively according to the Successive Approximation Model (SAM) in game-based learning due to Vallance et. al. [10].

For the first time we experimented with supporting the sequential project evaluation by play tokens. All projects are continually evaluated in project pitches and the teams are appropriately rewarded with play tokens. With these play tokens every team can purchase missing know-how or hire additional workforce. Interdisciplinary teamwork will promote social skills, social conventions, professional standards as well as language and writing skills. A continuous and transparent evaluation of the process makes the individual learning progress directly tangible.

\section{Serious Games - Application AREAS AND REQUIREMENTS}

social sciences. Most important for a realistic simulation game is the use of real interfaces and accessories.

According to Banks [13], Fernndez-Izquierdo et. al [14] and Law [15] there are seven application areas of simulation. When we add entertainment, sports and tourism we end up with ten different application areas. Today all these application areas use forms of Applied Interactive Technologies (APITs) for simulation purpose. The APITs networking matrix [16] (Fig. 1.) shows intersectoral relations and synergies.

This matrix quotes the application areas on the vertical $y$-axis and the sustainable value chain on the horizontal $\mathrm{x}$-axis. The application areas are parted into products (above) and services (below). The products are organized by scale from kilometer scale in city planning to nano scale in life sciences and down to no-scale in entertainment.

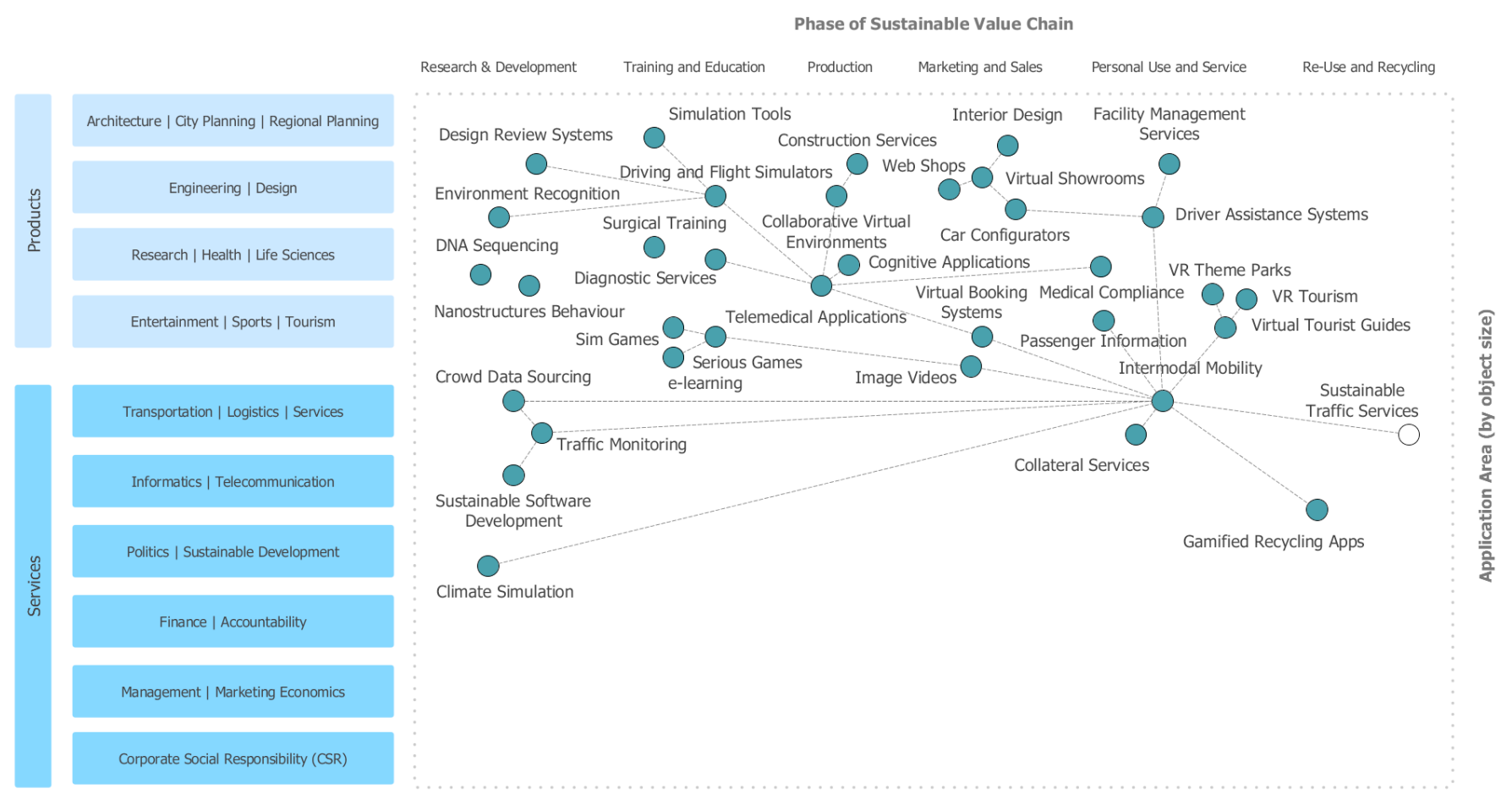

Fig. 1. APITs networking matrix showing intersectoral smart crosslinking

Apperley [11] designates seven different categories of game genres - action, adventure, arcade, roleplay, strategy, simulation (sim games) and casual games. While sim games form a specific genre, serious games can appear in all game genres as a category of their own. Aldrich [12] calls sim games "The new media of 'Learning to Do', not just 'Learning to Know'." Sim games depict a specific and unique part of the reality. Thus they form an abstract and operable model. Within this model the player can change certain parameters and run through various scenarios. This is tried and tested practice today in engineering, economics, management and
In the field between both axis we can observe intersectoral synergies, interrelated software developments and smart crosslinking. It is shown, that $3 \mathrm{D}$ architectural visualization is closely interrelated with other important sectors such as politics and sustainable development, transportation, regional and city planning as well as engineering, design, entertainment and last but not least tourism and other urban services. So interdiciplinary crosslinking will be very important for a functional game-based approach for 3D architectural visualization. Therefore our business game concept should reflect the exact tasks, tools and partners of a professional 3D architectural visualization, like in a functional economic simulation or a strategy game. 


\section{Related Work - Business GAMES FOR EdUCATION}

Business games are generally used for teaching certain skills. Since their beginnings in the mid of the 20th century their concepts were mainly related to defence, economics or the business world. Often they are occupied with corporate or business management, finances, human resources, negotiations or trading, such as the INTOP project by Graves et. al. [17]. Legendary other business games were the 'Lemonade Stand' designed for Apple in the 1970s, the 'Beer Distribution Game', designed by the business school at the Massachusetts Institute of Technology (MIT) in the end of the 1960s, as well as 'Sim City' followed by 'Cities Skylines' and 'Merchants'. There are different forms of business games used in education today. Just to mention a few examples Jesmin and Ley [18] use online platforms for knowledge building, while Polys et. al. [19] developed a 3D GIS interactive visualization to enhance environmental awareness. Berger et. al. [20] presented an eBusiness environment in form of a Massive Multi-User Online Role-Playing Game (MMORPG).

Let us assume Applied Interactive Technologies to be organized in five basic elements with coherent subsets [21] (Fig. 2.): user, application area, content, phase of value chain and technology. This assumption is compliant to Apperley's four main game elements of platform, genre, mode and millieu [11] and it integrates Schell's comprehensive game model containing aesthetics, story, mechanics and technology [22]. Thus business games can combine different game genres, depiction methods (e.g. VR,MR,AR), use different platforms (e.g. PC, mobile, web, etc.) and contain different elements of gamification, such as ranking and rewards, due to the referring target group. So business games use preferably both, digital and analogue elements and tools.

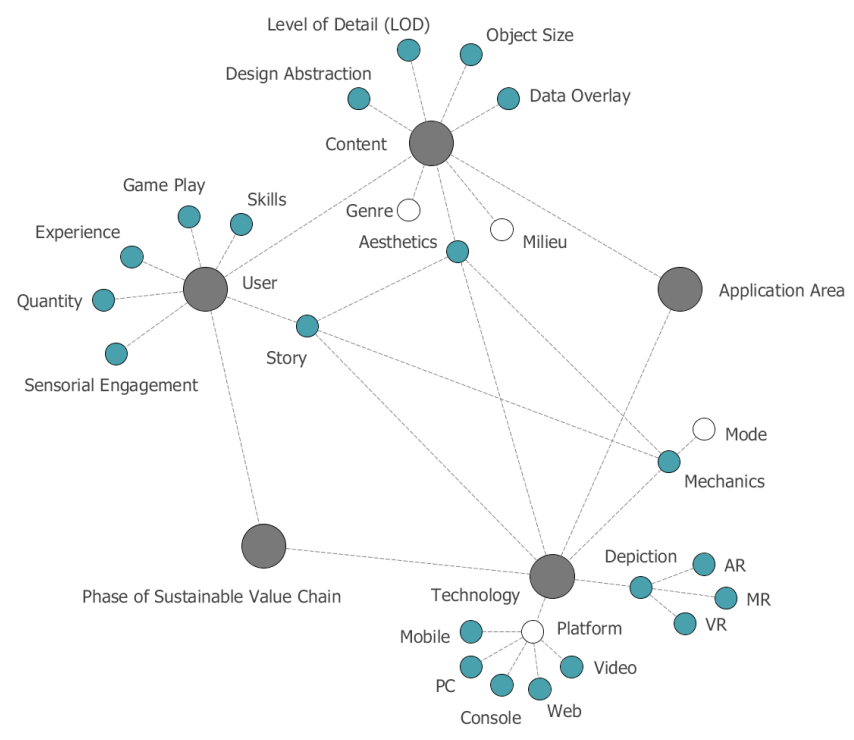

Fig. 2. Basic Elements of Applied Interactive Technologies.

\section{A Business Game For 3D ARChitectural VISUALIZATION}

In winter term 2017/2018 the course "Visualisierung 1" took place for the first time in the form of a business game. We decided to combine different depiction methods (analogue and digital, linear and interactive), platforms, game genres (roleplay, strategy and simulation) and selected elements of gamification, such as a tokenized rewarding system. The whole experimental setup should be as close to the real conditions of a professional 3D architectural visualization and should contain as much playful and dynamic tasks as compatible. So we stressed interdisciplinarity in teams and introduced a new way of continuous evaluation using the Sequential Evaluation Approach. We used project pitches for evaluation and distinguished between user evaluations and expert evaluations due to the roles of the respective evaluators. So the participants and the lecturer will have changing roles in the continuous process of the business game. Real interfaces and accessories, such as professional software packages and workflows were used. This business game should improve teamwork, social skills and collaboration. Our teaching evolution had the following goals:

- Open forms of teaching for the active acquisition of basic knowledge (bar camp, open space)

- Game-based learning to strengthen transfer competence and understanding of technology

- Integration of existing media usage habits (connectivity)

- Promotion of social soft skills, language and writing skills (community)

- Reflection of the product and service orientation of the students (convenience)

- Transparency of learning progress through continuous evaluation (gamification)

The whole course worked like a 'bar camp'. It uses targeted external digital platforms (e.g. Wikipedia, social media, YouTube, Vimeo, qualified digital forums and professional platforms for 3D animation) and existing digital offers of the university (e.g. Moodle, OwnCloud, interactive whiteboards) integrated into the classroom. Additionally the students should feel free to use their own favoured 3D software packages. The students formed cooperative and interdisciplinary teams. These teams should work like a small stand-alone business. As part of the business game, students complete all steps in the professional production of a 3D animation. They describe and calculate their performance, make offers, prepare contracts, purchase missing know-how, hire additional workforce, coordinate production, implement all product stages and professionally settle all services. The lecturer has three roles: he is the client, managing director and the $3 \mathrm{D}$ consultant. This multilateral exchange should strengthen the community. Technological foundations, technical structures, social conventions and professional standards can thus be communicated more effectively. 
There are four lesson blocks comprising two days. In the first block (sprint), a compact 3D animation will be designed and implemented under supervision by every team. The results are pitched and rewarded appropriately with a defined amount of play tokens. As a result, the students get to know the general course of the business game. In the following three lesson blocks, students can independently develop a larger project. In an open space setting several parallel sessions and workshops take place. The students can actively shape the individual workshops. All interim results are evaluated continually in the collective plenum according to design and economic criteria.

\section{Conclusions}

The results of the course were exceptionally good. Four interesting and professionally completed 3D visualization projects were created:

- 3D animation of a single-family dwelling as the seasons change (Seasons Change Animation)

- Virtual Reality Architectural Walk-Through using HTC Vive (Team VR)

- 3D animation of an industrial hall (Animated Axonometry)

- Image movie for a solar provider

All teams were evaluated positively. The team 'Seasons Change Animation' was best rated (443 design points and the highest remaining play token budget). 'Team VR' (Fig. 3.) won the second prize (422 design points and the second high play token budget). On the third place we found 'Animated Axonometry' (398 design points and the third high remaining play token budget).

The concept of a business game was a visible success. The design and technical standard were far above the work of the past years. The students were not only able to acquire new content more easily and quickly, but also their high degree of personal responsibility led to outstanding new ideas and their own initiatives. In general, this new course form was also well received by the students. The continuous professional evaluation was rated very positively, while the handling of the play-money budgets was often not quite comprehensible to the students. Students who took part in the business game reported more enjoyment in learning the $3 \mathrm{D}$ visualization pipeline than students from the years before. The business game induced greater interest to the students in acquiring new content more easily and quickly than in the other courses. Also their high degree of personal responsibility led to outstanding new ideas and their own initiatives.

\section{ACKNOWLEDGMENT}

I would like to express my very great appreciation to Wolfgang Schmied, the manager of our master program for enabling and establishing this new and experimental lecture format at our university. This project would have been impossible without the well-founded support of our leading software and system specialist Gerhard Schmidt and all the endorsement from our master course's and central administration, especially performed by Andrea Simbürger.

\section{REFERENCES}

[1] H. Weinreich, H. Obendorf, E. Herder and M. Mayer, "Not Quite the Average: An Empirial Study of Web Use", in: ACM Transactions on the Web, January 2008 (2008)

[2] W. Koch, B. Frees, ”ARD/ZDF-Onlinestudie 2017 - Neun von zehn Deutschen online". in: Media Perspektiven, 9 (2017), 434 446. 2

[3] C. Hartmann, "Den Geist entrmpeln", in: Die Zeit Wissen Nr.3/2019 vom 2019-04-16 (2019)

[4] C. Scholz, "Generation Z - Digital Native oder digital naiv?", in: HR Performance, DATAKONTEXT GmbH., Frechen, 1 (2015), 6871. 1,2

[5] N. Bleuel, N. Heinen and T. Stelzer, "Wir waren mal schlauer", in: Die Zeit Nr. 14/2019 vom 2019-03-27 (2019)

[6] S. Alexander, "Flexible learning in higher education", in: Penelope Peterson, Eva Baker and Barry McGaw (eds. in chief): International Encyclopedia of Education, Third Edition, Elsevier, Oxford, 441447. 2 (2010)

[7] H. Owen, "Open Space Technology - Ein Leitfaden fr die Praxis". KlettCotta, Stuttgart, 2001. 2 (2001)

[8] Doug Bowman, "3D User Interfaces: Theory and Practice". Course Smart, eTextbook, Addison-Wesley, 2004. 3

[9] J. L. Gabbard, D. Hix, J. E. Swan, "User-centered design and evaluation of virtual environments". in: IEEE Computer Graphics and Applications, 19.6 (1999), 5159. 3

[10] M. Vallance, Y. Kurashige, T. Sasaki, T. Magaki, "Development of a synthetic learning environment in the antidisciplinary space". in: Proceedings of the 11th European Conference on Game-Based Learning ECGBL 2017, FH JOANNEUM University of Applied Sciences, Graz, Austria (4-6 Oct 2017), 705714. 3

[11] T. B. Apperley, "Genre and Game Studies - Toward a critical approach to video game genres", in:Simulation and Gaming, March 2006 (2006)

[12] C. Aldrich, "The Complete Guide to Simulation and Serious Games", John Wiley and Sons. (2009)

[13] J. Banks, "Handbook of Simulation", John Wiley and Sons (1998)

[14] M. . Fernndez-Izquierdo, M. J. Munoz-Torres, R. Len (eds.), "Modeling and Simulation in Engineering, Economics and Management", in: Proceedings of the International Conference, MS 2013, Castelln de la Plana, Spain, June 6-7, Springer Heidelberg Dordrecht London n New York (2013)

[15] A. M. Law, "Simulation, Modeling and Analysis, McGraw Hill (2007)

[16] W. Höhl, "Open Innovation and Applied Interactive Technologies (APITs)", Poster presentation at SAP 2017 ACM Symposium on Applied Perception, 16-17 September 2017, Brandenburg University of Technology in Cottbus, Germany (2017)

[17] R. L. Graves, L. Howells and H. B. Thorelli, "INTOP, an International Business Game", in: Proceedings of the 1961 16th ACM national meeting, University of Chicago (1961).

[18] T. Jesmin and T. Ley, "Investigating teachers practices of using games in school: A pattern-based approach", in: Proceedings of ACM OpenSym 16 Berlin, Germany (2016)

[19] N. Polys, J. Hotter, M. Lanier, L. Purcell, J. Wolf, W. C. Hession, P. Sforza and J. D. Ivory, "Finding Frogs: Using Game-Based Learning to Increase Environmental Awareness, in: Proceedings of Web3D '17, June 05-07, 2017, Brisbane, QLD, Australia (2017).

[20] H. Berger, M. Dittenbach, D. Merkl, A. Bogdanovych, S. Simoff, C. Sierra, "Playing the e-Business game in 3D Virtual Worlds", in: Proceedings of OZCHI 2006, November 20-24, 2006, Sydney, Australia (2006)

[21] W. Höhl, "Interdisciplinary Integration Transportation and Applied Interactive Technologies" - Innovation survey by the Federal Ministery of Transport and Digital Infrastructure (BMVI), in: N. Boehnke, "Verkehr und Applied Interactive Technologies", BMVI - Stiftung Digitale Spielekultur, Berlin (2017)

[22] J. Schell, "The Art of Game Design - A Book of Lenses", Morgan Kaufmann Publishers, Elsevier Inc., Burlington (MA), USA. p. 42 (2008) 